\title{
Prevalence of SeXual dysfunction during PREgnancy
}

\author{
Alessandra Plácido lima Leite ${ }^{1 *}$, Ana Aurélia Salles Campos$^{2}$, Antonio Roberto Cardoso Dias ${ }^{3}$, Abes Mahmed Amed $^{4}$, Eduardo De Souza ${ }^{5}$, \\ Luis Camano ${ }^{6}$ \\ Trabalho realizado na Universidade Federal de São Paulo - UNIFESP, Universidade Estadual de Ciências da Saúde de Alagoas - Faculdade de Medicina, Maceió, AL
}

*Correspondência:

Trav. Sebastião da Hora, 204

Gruta de Lourdes

Maceió-AL

$57052-835$

\begin{abstract}
SUMMARY
OвJective. This study aims to evaluate the sexual function and to determine the prevalence of sexual dysfunction among teenagers and adult women during pregnancy using the Female Sexual Function Index (FSFI).

MetHods. A cohort study was conducted with 271 healthy pregnant women presenting a stable relationship with their partners. These women contributed to the survey since the laboratory diagnosis of their present pregnancy. Anonymous questionnaires evaluated aspects of sexual activity and female sexual function. This last item was assessed through the FSFI questionnaire.

Results. The women sexual function showed a similar pattern during the first and second trimesters; however, it presented a significantly clear decrease in the third trimester. There was a significant difference in the scores of all FSFI domains when comparing the second and third trimesters. The sexual dysfunction among pregnant teenagers was rated $40.8 \%$ in the first trimester, $31.2 \%$ in the second and $63.2 \%$ in the third. For pregnant adults, the dysfunction was rated, respectively, $46.6 \%$, $34.2 \%$ and $73.3 \%$.

ConcLusion. The sexual function is affected during pregnancy with a significant decrease in all FSFI domains in the third trimester considering both pregnant teenagers and adults. Prevalence of sexual dysfunction is high during pregnancy and reaches higher levels in the third trimester in both age groups; however, teenagers presented better sexual function ratings.
\end{abstract}

KEY wORDS: Sexual dysfunction. Pregnancy. Orgasm.

\section{INTRODUCTION}

Pregnancy plays an important role in the sexual function and behavior of women. ${ }^{1,2,3}$ Even though $86 \%$ to $100 \%$ of couples continue sexually active during the gestational period, most women show a decrease in the coital frequency and sexual desire - mainly in the third trimester of pregnancy. ${ }^{4,5,6}$ Problems of sexual function are commonly reported among pregnant women. 1,3,7

Several studies have been developed showing that sexual dysfunction seems to be a very frequent health problem. Such a problem is observed in $25 \%$ to $92 \%$ of women ${ }^{8,11-14}$. The sexual function can be affected by age, education, chronic diseases, pregnancy and parity .1,8,10,11,15

The importance of sexual health for quality of life has become more evident nowadays. ${ }^{16}$ Sexual dysfunction might cause a huge impact on women's quality of life since the decrease in sexual function can have negative effects on self-esteem and interpersonal relationships. Frequently, such sexual dysfunction may cause emotional distress ${ }^{8}$. Studies have shown a significant association between sexual dysfunction and unsatisfactory physical and emotional findings ${ }^{8,17}$.

Despite the increasing number of epidemiologic studies, there are no sufficient data in medical literature regarding prevalence of sexual dysfunction during pregnancy. Based on this premise we used the Female Sexual Function Index questionnaire (FSFI) ${ }^{17}$ to comparatively evaluate the sexual function and prevalence of sexual dysfunction in two age groups (teenagers and adults) in the three gestational trimesters.

\section{Methods}

A prospective sample study was conducted between April 2005 and January 2007 using 271 healthy pregnant women presenting a stable marital status in the previous six-months.

1. Professora da Universidade Estadual de Ciências da Saúde de Alagoas - UNCISAL, Maceió, AL

2. Professora da Universidade Estadual de Ciências da Saúde de Alagoas - UNCISAL, Maceió, AL

3. Pós-Graduando da Universidade Federal do Estado de São Paulo - UNIFESP, São Paulo, SP

4. Professor da Universidade Federal do Estado de São Paulo - UNIFESP, São Paulo,SP

5. Livre-Docente da Universidade Federal do Estado de São Paulo - UNIFESP, São Paulo, SP

6. Professor Titular da Universidade Federal do Estado de São Paulo - UNIFESP, São Paulo,SP 
Patients contributed to this survey since laboratory diagnosis of pregnancy. Two distinct groups were considered: the first with pregnant teenagers age 19 and under; the second with pregnant adults (over 20 years old). In the first prenatal evaluation, as well as in those following, the women completed the FSFI questionnaire in separate rooms to preserve privacy of the study. All patients answered the questionnaire each trimester. The gestational age was confirmed by the last menstrual period and by transvaginal ultrasound (performed up to the $14^{\text {th }}$ gestational week).

Consultation and prenatal evaluation routines were the same throughout pregnancy. During the survey, women who presented maternal-fetal complications or co-morbidities that could determine sexual restrictions were excluded from the study.

The FSFI is a valid and accurate measure of the female sexual function. This questionnaire comprises 19 questions that evaluate six different domains of sexual function including desire, arousal, lubrication, orgasm, satisfaction and pain. ${ }^{17}$ Questions $1,2,15$ and 16 were scored from 1 to 5 ; all the others were scored from 0 to 5 . Each domain score was obtained by adding individual items of the domain and multiplying this result by the domain factor (i.e. desire, 0.6; arousal and lubrication, 0.3 ; orgasm, satisfaction and pain, 0.4 ). The FSFI total score is determined by the sum of the six domains and can vary from 2 to $36^{17}$, where higher scores are associated to the lower degree of sexual dysfunction. Since a total score of 26 is the cutoff point for women with sexual dysfunction ${ }^{18}$, the present study considered patients that were scored 26 and under as presenting the disorder. The FSFI information was translated to Portuguese and previously validated for Brazilian pregnant women. ${ }^{19}$

Data were analyzed by the program SPSS 11.5. The score of each domain was calculated and its average was compared - according to the women's age and gestational trimester. The FSFI average scores were compared between the age groups (independent samples) and the gestational trimesters (related samples), using for the first comparison the Mann-Whitney non-parametric test; for the second comparison, the Friedman test (in the three trimesters) and the Wilcoxon test (between two consecutive trimesters). Non-parametric tests were used because scores did not present a normally balanced distribution in comparison with one another. Then, the average scores were compared in the six FSFI domains using the same tests mentioned above. A complementary analysis was undertaken dichotomizing samples using the cutoff 26.0 in the FSFI general score to evaluate the sexual dysfunction percentage. The non-parametric tests used were the Yates chi-square test (independent samples) and the Cochran and McNemar tests (related samples). Differences were considered statistically significant when $p<0.05$. This survey was approved by the institution Ethics and Research Committee after all pregnant women had given their written consent.

\section{RESULTS}

The initial sample had 294 pregnant women: seven patients in the first trimester (04 miscarriages, 02 miscarriage threats, 01 hospital admission due to gravidic hyperemesis), eight in the second (02 miscarriages, 03 miscarriage threats, 03 premature ruptures of the ovular membranes), and eight in the third trimester
(03 premature labors, 02 premature ruptures of the ovular membranes, 02 genital bleedings, 01 hospital admission due to severe preeclampsia) were excluded because they presented clinical conditions restricting sexual activity during pregnancy. Data of 271 pregnant women are analyzed at the end of this study.

Most patients were adults (53.9\%) and nulliparous (65.3\%). The teenagers mean age was 17.2 with a variation of \pm 1.5 years and parity was $0.1 \pm 0.2$ children per woman. Among the adults mean age was 25.7 with a variation of \pm 4.5 years and parity was $0.5 \pm 0.7$ children per woman.

Domains of the FSFI scores established for survey during pregnancy are presented in Table 1. There was a significant difference in the median scores in the FSFI domains throughout pregnancy, specifically in the third trimester. In this case, there was a significant decrease in the score of all FSFI domains when compared to the second trimester $(p<0.001)$.

Comparing the sexual function considering patients age, there was a statistically significant difference between the teenagers and adults in the third trimester $(p=0.008)$. Within this group, the adults presented a lower mean score. There was no difference in the sexual function results in the first and second trimesters. When comparing domains scores individually, it was observed that in the first trimester, desire and pain presented a significant difference according to the age group. In the second trimester, pain was the only indicator with a relevant difference. Although an important difference was not noticed in most of the domains in the first and second trimesters, all domains presented an expressive difference between pregnant teenagers and adults in the third trimester - pain was the only exception.

Prevalence of sexual dysfunction in the first trimester was rated $40.8 \%$ among pregnant teenagers and $46.6 \%$ among adults. This same dysfunction was rated respectively $31.2 \%$ and $34.2 \%$ in the second trimester and, in the third trimester, $63.2 \%$ and $73.3 \%$. It is important to note that no relevant statistical difference was recorded among the observed groups (Table 2). A very important difference was found in the prevalence of sexual dysfunction in the general comparison, specifically between the second and third gestational trimesters $(p<0.001)$.

\section{Discussion}

Painless and satisfactory sexual intercourse (which is an important component to establish the relationship of many couples) is frequently influenced by gestational physical and emotional demands. ${ }^{15}$ The effect of these factors over the pregnant woman's sexual life can have a wide range of variation, reflecting the idiosyncratic nature of human sexuality. ${ }^{20}$

Sexual activity and the pregnant sexuality have been widely researched. However, prospective studies that evaluate pregnant women sexual function are rare and limited. Further, no study about the sexual dysfunction prevalence during pregnancy was found in medical literature by the authors.

In this survey we utilized the FSFI - which is a valid and safe measurement of the female sexual function. The FSFI presents domains that reflect the female sexual response and pain. ${ }^{16}$ As far as we know, this study is the first one using the FSFI score as an instrument to detect pregnant women with sexual dysfunction; this cutoff determines the prevalence of sexual dysfunction during pregnancy using a sample of 271 women. 
The FSFI was chosen for this study because it is a specific and multidimensional research instrument, following the evolution of new concepts of female sexual dysfunction. ${ }^{17}$ It also allowed comparison of our results with other studies using similar methodology for pregnant samples. Not long ago, most studies were related to prospective samples - and not to cross sectional ones. Results of several studies about the association between pregnancy and sexual dysfunction could not be directly compared because different definitions and methods were used to evaluate the sexual function during gestation. 1,7
In the present study, significant changes were found in all FSFI domains during pregnancy with a slight decrease of the sexual function in the first trimester. There were, however, better indicators in the second trimester and a strong decrease in the final trimester. In Masters and Johnsons' studies, sexual response patterns were defined during pregnancy, which were very similar to those in our study. In a meta-analysis of 59 studies von Sydow observed that, during the gestational period, sexuality is likely to slightly decrease in the first trimester. In the second, there

Table 1. Average score and standard deviation of FSFI domains according to the age and gestational trimesters.

\begin{tabular}{|c|c|c|c|c|c|c|}
\hline \multirow{2}{*}{$\begin{array}{l}\text { FSFI/ Domain } \\
\text { Age (in years old) }\end{array}$} & \multicolumn{3}{|c|}{ Trimester } & \multirow[t]{2}{*}{$p$ * } & \multirow{2}{*}{$\begin{array}{c}p * * \\
\left(1^{\circ} \times 2^{\circ}\right)\end{array}$} & \multirow{2}{*}{$\begin{array}{c}p^{* *} \\
\left(2^{\circ} \times 3^{\circ}\right)\end{array}$} \\
\hline & $1^{0}$ & $2^{0}$ & $3^{\circ}$ & & & \\
\hline \multicolumn{7}{|l|}{ Desire } \\
\hline Up to 19 years old & $3.90[1.28]$ & 3.98 [1.09] & 3.28 [1.18] & $<0.001$ & 0.313 & $<0.001$ \\
\hline$\geq 20$ & 3.59 [1.20] & $3.76[1.25]$ & $2.77[1.31]$ & $<0.001$ & 0.117 & $<0.001$ \\
\hline$p * * *$ & 0.036 & 0.141 & $<0.002$ & & & \\
\hline \multicolumn{7}{|l|}{ Arousal } \\
\hline Up to 19 years old & $4.05[1.40]$ & $4.22[1.18]$ & $3.24[1,80]$ & $<0.001$ & 0.627 & $<0.001$ \\
\hline$\geq 20$ & $4.00[1.24]$ & $4.23[1.16]$ & $2.62[1.89]$ & $<0.001$ & 0.135 & $<0.001$ \\
\hline$p * * *$ & 0.314 & 0.930 & 0.005 & & & \\
\hline \multicolumn{7}{|l|}{ Lubrication } \\
\hline Up to 19 years old & 4.74 [1.45] & $4.96[1.32]$ & 3.87 [2.13] & $<0.001$ & 0.191 & $<0.001$ \\
\hline$\geq 20$ & $4.86[1.30]$ & $4.97[1.23]$ & $3.21[2.28]$ & $<0.001$ & 0.789 & $<0.001$ \\
\hline$p * * *$ & 0.471 & 0.984 & 0.015 & & & \\
\hline \multicolumn{7}{|l|}{ Orgasm } \\
\hline Up to 19 years old & $4.29[1.59]$ & $4.46[1.39]$ & 3.44 [1.93] & $<0.001$ & 0.349 & $<0.001$ \\
\hline$\geq 20$ & $4.41[1.43]$ & $4.48[1.36]$ & $2.86[2.13]$ & $<0.001$ & 0.672 & $<0.001$ \\
\hline$p * * *$ & 0.703 & 0.920 & 0.028 & & & \\
\hline \multicolumn{7}{|l|}{ Satisfaction } \\
\hline Up to 19 years old & $4.92[1.34]$ & $4.97[1.27]$ & $4.14[1.74]$ & $<0.001$ & 0.857 & $<0.001$ \\
\hline$\geq 20$ & $4.95[1.21]$ & $4.80[1.27]$ & $3.29[1.80]$ & $<0.001$ & 0.214 & $<0.001$ \\
\hline$p * * *$ & 0.728 & 0.180 & $<0.001$ & & & \\
\hline \multicolumn{7}{|l|}{ Pain } \\
\hline Up to 19 years old & 4.19 [1.56] & $4.22[1.57]$ & $3.44[2.01]$ & $<0.001$ & 0.776 & $<0.001$ \\
\hline$\geq 20$ & $4.60[1.44]$ & $4.67[1.41]$ & $3.38[2.45]$ & $<0.001$ & 0.547 & $<0.001$ \\
\hline$p * * *$ & 0.010 & 0.009 & 0.526 & & & \\
\hline \multicolumn{7}{|l|}{ Total } \\
\hline Up to 19 years old & $26.90[6.79]$ & $26.81[5.82]$ & 21.40 [9.43] & $<0.001$ & 0.493 & $<0.001$ \\
\hline$\geq 20$ & $26.41[6.04]$ & 26.91 [5.92] & 18.13 [10.98] & $<0.001$ & 0.500 & $<0.001$ \\
\hline$p * * *$ & 0.943 & 0.872 & 0.008 & & & \\
\hline
\end{tabular}

[ ] Standard deviation;

* Friedmans non-parametric test for three related samples;

** Wilcoxons non-parametric test for two related samples;

*** Mann-Whitneys non-parametric test for two independent samples. 
Table 2. Sexual dysfunction\# percentage for pregnants, according to the age and gestational trimester

\begin{tabular}{|c|c|c|c|c|c|c|c|}
\hline \multirow{2}{*}{$\begin{array}{l}\text { Age } \\
\text { (in years old) }\end{array}$} & \multicolumn{3}{|c|}{ Trimester } & \multirow[t]{2}{*}{$p$ * } & \multirow{2}{*}{$\begin{array}{c}p * * \\
\left(1^{0} \times 2^{\circ}\right)\end{array}$} & \multirow{2}{*}{$\begin{array}{c}p * * \\
\left(2^{\circ} \times 3^{\circ}\right)\end{array}$} & \multirow[b]{2}{*}{ (n) } \\
\hline & $1^{0}$ & $2^{\circ}$ & $3^{\circ}$ & & & & \\
\hline$\geq 20$ & 46.6 & 34.2 & 73.3 & $<0.001$ & 0.016 & $<0.001$ & (146) \\
\hline$p^{* * *}$ & 0.405 & 0.687 & 0.098 & & & & \\
\hline
\end{tabular}

"General FSFI score $\leq 26.0$ (with dysfunction);

* Cochrans non-parametric test for three related samples;

** McNemars non-parametric test for two related samples;

*** Yates chi-square test (with continuity correction) for teenagers and adults.

is a variable pattern and in the third, it presents an expressive decrease $^{7}$ - confirming the results of our study.

The second gestational trimester is considered the most emotionally stable period of gestation when pregnancy seems to be clearly established - diminishing, this way, fear of fetal loss. Reaffirmation of feminility through the duo woman/maternity associated to the pregnant pelvis vascular changes and to the cessation of nausea - allows an increase in orgastic quality as well as in the level of erotism. These factors can explain the presence of the sexual function's best indicators in the second trimester - which was already mentioned in this article.

In the present work, changes in the scores of all domains were not significant between the first and the second trimesters. These results were also observed by Aslan et al, ${ }^{1}$ who evaluated pregnant women sexual function using the FSFI throughout pregnancy. However, when comparing the second and the third trimesters, a significant difference was noted in scores of all domains. Confirming our findings, several studies showed a strong decrease of the sexual function and activity in the third trimester. ${ }^{1-7,15,20,21}$

The final trimester of pregnancy is characterized by significant changes in the woman's body. These changes could be the reason for the decrease in libido and sexual activity during this period. Increase of both the abdominal volume and fetal weight - cause lack of balance and compensatory postural changes - forcing the female organism to begin using muscles seldom used before pregnancy, which can cause lumbar pain - a specific symptom of the gestational period's end. Also, fatigue, anxiety and the natural fear felt due to proximity of labor tend to make the sexual relationship unattractive for pregnant women. Another factor that contributes to decrease the female sexual function is the partner's loss of sexual interest because of worries with the woman and the baby, as well as the non-erotic effect of the woman's appearance at the end of pregnancy.

Considering the pregnant women age group, when comparing individual scores of each FSFI domain, it was observed that all domains showed a significant difference in the third trimester except pain. Analyzing the first and second trimesters, the only domain presenting an expressive difference was pain. Curiously, dyspareunia decreased in the third trimester in both age groups, probably due to decrease of vaginal coitus attempts. This finding differs from the one found in medical literature where an increase of dyspareunia is reported in the third trimester. ${ }^{1,6,7}$
Probably some specific teenagers' characteristics - inherent to their age group - must have contributed to reach a better index of sexual function in this group. Curiosity regarding sexual intercourse, novelty about the recently started sexual relationship and belief that nothing bad could possibly happen - besides the fact that most were nulliparous - helped adolescents to have better sexual activity. Among the pregnant adults, factors like parity (most of them already had one or more children), the triple and exhaustive workload (performed only by the female gender who takes care of several things at once - the house, the children, the husband, the job) and virtual issues in the sexual relationship could be, in fact, the main reasons for a worse sexual performance. As said before, this could be explained by a greater interest in the recently undertaken sexual activity - besides the biopsychosocial characteristics of the teenager group; all these factors, however, may not be sufficient to explain the recent findings. Maybe we have to consider the teenager's different psychism present in the case of a pregnancy. Pregnant teenagers hardly ever consider themselves pregnant, and hardly ever see themselves as mothers. This is why teenagers do not experience the psychological conflicts of adult women during pregnancy. Analyzed from this point of view, some might consider that teenagers present a transitory dysfunction - and maybe even a regular status which adapts to the moment (considering that short events of sexual dysfunction would not properly be a problem). As an example, Ferenidou et al. ${ }^{23}$ present a study where $80.5 \%$ of the interviewed women considered their sexual lives as "still satisfactory", although $48.8 \%$ were diagnosed by the FSFI as women with sexual dysfunction. Even though we respect this point of view, it is difficult to consider "normal", something that still causes suffering. We prefer to understand this behavior, more as a result of the so-called "magic thinking" of the adolescence, than as a peculiarity of their sexual behavior.

In this study prevalence of sexual dysfunction showed significant alterations throughout pregnancy. In the first trimester it was high; in the second, it presented a slight decrease; and in the third, there was a very significant increase. These results reassert the influence of pregnancy on women sexual function and activity as observed in other studies. ${ }^{1-7,14,15,20,21}$

In this study, some findings corresponded to the initial expectations - especially the emphatic decline of sexual function and activity in the third trimester and the greater prevalence of sexual dysfunction among adults throughout pregnancy - even 
though this dysfunction was not significant within the age groups. However, other findings were different from the expected, such as the similar sexual function in the first and second trimesters (with a slight increase in the second), absence of differences within age groups in general and decrease of dyspareunia in the third trimester.

When trying to explain the unexpected findings, we can deduce that women in Alagoas - and probably from all the Northeast of Brazil - do not hold a strong position during "sexual negotiations". Brazilian pregnant women probably have difficulty in saying "no" to their partners. It is possible that we had a "superdiagnosis" of sexual dysfunction in the first and second trimesters once the values of FSFI scores were established for a population which is very different from the Brazilian and for women who were not pregnant. However, in the future, other authors could conduct a new FSFI cutoff study with values established for the Brazilian population or for pregnant women in general.

Considering that biological factors are involved in the origin of sexual dysfunction, 10 the absence of an androgen profile investigation of women during pregnancy could be considered a shortcoming in this survey. However, in a recent study Erol et al. ${ }^{22}$ perceived that serum androgen levels did not change during pregnancy and that they did not relate with the sexual dysfunction found during pregnancy.

Interpersonal and psychological factors were not evaluated in this survey. The sexual satisfaction during pregnancy is strongly associated to increase of the couple's emotional bond, as well as to the pregnant women confidence and self-esteem. Those who are physically and emotionally nurtured during pregnancy become more confident. If such women feel they are still attractive to their partners even when perceiving their physical changes, there is a tendency to boost their self-esteem; this has a positive influence on the couple's sexual acitivity. Accordingly, the male partner has a great responsibility in the female partner's sexual life. Thus, it is evident that changes in FSFI scores among pregnant women in this survey can be directly linked to elements related to their partners. However, in the present study evaluation of the pregnant's partners was not made because the partners never attended prenatal evaluations, even after receiving several verbal and written invitations. Furthermore, the pregnant one- as well as her partner - worry about the consequences of sexual activity on pregnancy. It should be emphasized that lack of information regarding sexual issues, as well as prejudice related to such matters, can worsen sexual dysfunction during the gestational period.

Better studies can be proposed. A larger casuistry could offer stronger statistics with results fully attributed to the population. Multicentric studies - especially international ones - could reduce cultural barriers when interpreting results. Another study can also be proposed - the comparison of pregnant and non-pregnant women's sexuality within an age-matched control group and a parity-matched control group. Furthermore, future studies would be enriched by the inclusion of male partners in the survey - moreover, because satisfaction regarding the sexual life of a man and a woman in a stable relationship has the same advantages for both.

With this study we hope to alert health-care providers in charge of prenatal care to pay attention to eventual sexual difficulties of pregnant women. They should adopt the necessary measures to prevent or treat these difficulties. Pregnant women are sexual. It is unacceptable when health professionals are negligent towards their complaints regarding this matter.

The present survey showed that the sexual function is affected during pregnancy with a significant decrease in all FSFI domains in the third trimester in both age groups - even though this decrease was more easily noticed and more emphatic among adults - and that the prevalence of sexual dysfunction is high during pregnancy. Sexual conflicts during pregnancy can cause serious disruptions in the relationship of the couple. Based on this statement, health-care providers in charge of prenatal care should provide orientation regarding sexual issues which should reinforce sexual response during pregnancy, contributing in this way, to the well-being of the couple in question.

Now we note that, during pregnancy, sexuality seems to have rules or functional habits which can be related to this period of human life to determine changes and adjustments in the couple's sexual patterns. Perhaps in the future we will discover that what now is diagnosed as dysfunctional may actually be the common sexual behavior in pregnancy, although this may be a reason for many women or couples to suffer.

\section{Conclusion}

We probably have to reformulate the concept of sexual normality during pregnancy. However, until now we believe that people do have some kind of sexual difficulty during pregnancy. This belief is still challenging. And we do hope that other researchers also feel stimulated to face this challenge.

\section{Conflict of interest: none}

\section{Resumo}

Prevalência da disfunção sexual na Gravidez

OBjetIvo. Avaliar a função sexual e determinar a prevalência da disfunção sexual em mulheres adolescentes e adultas durante a gravidez, usando o Índice da Função Sexual Feminina (FSFI).

Métodos. Realizou-se estudo de corte prospectivo com 271 gestantes saudáveis, envolvidas na pesquisa desde o primeiro diagnóstico da atual gravidez, que mantinham relacionamento estável com parceiro. Foram utilizados questionários anônimose a função sexual das gestantes foi avaliada pelo índice da função sexual feminina, em cada trimestre gestacional.

Resultados. Existiu diferença significante para os escores médios dos domínios do FSFI ao longo da gestação, mais especificamente no terceiro trimestre, onde houve diminuição significativa dos escores de todos os domínios do FSFI quando comparado ao segundo trimestre $(p<0,001)$. Quando a função sexual foi comparada de acordo com a idade da paciente, existiu diferença estatisticamente significante entre as gestantes adolescentes e adultas no terceiro trimestre $(p=0,008)$. A disfunção sexual entre as gestantes adolescentes foi de $40,8 \%$ no primeiro trimestre, 31,2\% no segundo e $63,2 \%$ no terceiro. Entre as grávidas adultas, foi de 46,6\%, 34,2\% e 73,3\% no primeiro, segundo e terceiro trimestres, respectivamente. Não 
existiu diferença significativa na prevalência da disfunção sexual quando comparada por faixa etária; entretanto, ao comparar por trimestre gestacional, houve diferença significante entre 0 segundo e o terceiro trimestre $(p<0,001)$.

Conclusão. A função sexual é afetada durante a gravidez, com significativo declínio de todos os domínios do FSFI no terceiro trimestre, tanto nas adolescentes quanto nas adultas. $A$ prevalência da disfunção sexual é elevada durante a gestação, atingindo níveis mais elevados no terceiro trimestre, em ambos os grupos etários, contudo as adolescentes apresentaram melhores índices de função sexual. [Rev Assoc Med Bras 2009; 55(5): 563-8]

Unitermos: Disfunção sexual. Gravidez. Orgasmo.

\section{REFERENCES}

1. Aslan G, Aslan D, Kizilyar A, Ispahi C, Esen A. A prospective analysis of sexual functions during pregnancy. Int J Impot Res. 2005;17:154-7.

2. Fok WY, Chan LKY, Yuen PM. Sexual behavior and activity in Chinese pregnant women. Acta Obstet Gynecol Scand. 2005;84:934-8.

3. Trutnovsky G, Haas J, Lang U, Petru E. womens perception of sexuality during pregnancy and after birth. Aust NZ J Obstet Gynaecol. 2006;46:282-7.

4. Bartellas E, Crane JM, Daley M, Bennett KA, Hutchens D. Sexuality and sexual activity in pregnancy. Br J Obstet Gynaecol. 2000;107:964-8.

5. Orji EO, Ogunlola IO, Fasubaa OB. Sexuality among pregnant women in South West Nigeria. J Obstet Gynaecol. 2002;22:166-8.

6. Gökyildiz S, Beji NK. The effects of pregnancy on sexual life. J Sex Marital Ther. 2005;31:201-5

7. Von Sydow K. Sexuality during pregnancy and after childbirth: a metacontent analysis of 59 studies. J Psychosom Res. 1999;47:27-49.

8. Laumann EO, Paik A, Rosen RC. Sexual dysfunction in the United States: prevalence and predictors. JAMA. 1999;281:537-44.

9. Basson R, Berman J, Burnett A, Derogatis L, Ferguson D, Fourcroy J, et al. Report of the International Consensus Development Conference on Female Sexual Dysfunction: definitions and classifications. J Urol. 2000;163:888-93.

10. Basson R. Womens sexual dysfunction: revised and expanded definitions. CMAJ. 2005; 172:1327-33.
11. Çayan S, Akbay E, Boslu M, Canpolat B, Acar D. The prevalence of female sexual dysfunction and potential risk factors that may impair sexual function in Turkish women. Urol Int. 2004;72:52-7.

12. Abdo CHN, Oliveira WM, Moreira Jr ED, Fittipaldi JAS. Prevalence of sexual dysfunctions and correlated conditions in a sample of Brazilian women results of the Brazilian study on sexual behavior (BSSB). Int J Impot Res. 2004; 16:160-6.

13. Nobre PJ, Pinto-Gouveia J, Gomes FA. Prevalence and comorbidity of sexual dysfunctions in a Portuguese clinical sample. J Sex Marital Ther. 2006;32:173-82.

14. Oksuz E, Malhan S. Prevalence and risk factors for female sexual dysfunction in Turkish women. J Urol. 2006;175: 654-8.

15. Eryilmaz G, Ege $E$, Zincir $H$. Factors affecting sexual life during pregnancy in eastern Turkey. Gynecol Obstet Invest. 2004;57:103-8.

16. Edwards WM , Coleman E. Defining sexual health: a descriptive overview. Arsh Sex Behav. 2004;33:189-95

17. Rosen R, Brown C, Heiman J, Leiblum S, Meston C, Shabsigh R, et al. The Female Sexual function Index (FSFI): a multidimensional self-report instrument for the assessment of female sexual function. J Sex Marital Ther. 2000; 26:191-208

18. Weigel M, Meston C, Rosen R. The Female Sexual function Index (FSFI): cross-validation and development of clinical cutoff scores. J Sex Marital Ther. 2005;31:1-20

19. Leite A, Moura E, Salles A, Mattar R, Souza E, Camano L. Validation of the Female Sexual Function Index in Brazilians pregnants. Rev Bras Ginecol Obstet. 2007;29:396-401

20. Solberg DA, Butler J, Wagnes NN. Sexual behavior in pregnancy. N Eng J Med. 1973;288:1098-103.

21. Masters WH, Johnson VE. A resposta sexual humana. Roca: São Paulo; 1984.

22. Erol B, Sanli O, Korkmaz D, Seyhan A, Akman T, Kadioglu A. A cross-sectional study of female sexual function and dysfunction during pregnancy. J Sex Med. 2007; 4:1381-7

23. Ferenidou F, Kapoteli V, Moisidis K, Koutsogiannes I, Giakoumelos A, Hatzichristou D. Presence of a sexual problem may not affect women's satisfaction from their sexual functions. J Sex Med. 2008;5:631-9.

Artigo recebido: 10/03/08 Aceito para publicação: 13/03/09 